\title{
Antitumor Activity of Novel Azole compound against Ehrlich Ascites Carcinoma in Swiss Albino Mice
}

\author{
Fawzia Zakaria ELAblack $^{1 *}$, Usama Bhgat Elgazzar ${ }^{2}$ and Ahmed hashem ${ }^{1}$ \\ ${ }^{1}$ Department Organic Chemistry, Damietta University, Egypt \\ ${ }^{2}$ Department Medical Biochemistry, Al-Azhar University, Egypt
}

*Corresponding author: Fawzia Zakaria ELAblack, Organic chemistry Department, Faculty of Science, Damietta University, Egypt.
Received Date: May 15, 2020

Published Date: June 23, 2020

\begin{abstract}
Background: Thiazole derivatives exhibited satisfactory antitumor activity towards various types of cancer.

Purpose: The present study was designed to evaluate the bioactivity of new synthesized Thiazole derivative against animal carcinogenesis "Ehrlich carcinoma)" (EAC) in mice through antioxidant status and regulation of apoptosis process.

Methods: To evaluate these effects we have explored the Thiazole effect on the survival time of tumor-bearing animals, tumor weight, count of viable EAC cells, apoptosis induction, antioxidant activity, liver enzymes and renal function compared to Cisplatin (CDDP) as a standard anticancer drug.

Results: Thiazole demonstrated an inhibitory effect on Ehrlich ascites cells in vivo by increasing in life span of Ehrlich-bearing mice, decrease in tumor volume and count of viable cells compared to control. Also revealed that Thiazole directed Ehrlich cells toward apoptosis by up regulation of $\mathrm{BAX}$ and down regulation of Bcl2 and PARP compared to Positive control groups. Treatment with Azole significantly decreased MDA level Meanwhile GSH and SOD Activity were significantly increased Compared to positive control group. While this compound showed hepatotoxicity which indicated that by increases in ALT and AST activities, and slight changes in kidney functions. The anti-tumor mechanisms may be mediated by up regulation of $\mathrm{BAX}$ and down regulation of Bcl2 and PARP compared to Positive control group.
\end{abstract}

Conclusion: Thiazole is a unique template that has anti-tumor mechanisms may be mediated by preventing oxidative damage, induction of apoptosis and improved animal chances of survival but clinical trials will be needed for development of Thiazole derivatives as cancer therapy.

\section{Introduction}

Cancer considered as a serious human health problem despite much progress in understanding its biology and pharmacology. Consequently, the design of new structures of antitumor agents is one of the most urgent research areas in contemporary medicinal chemistry. Cancer results from the fast creation of abnormal cells that spread to adjacent parts of the body and extend to other organs, this process is called metastasis. Metastasis is the major reason for cancer deaths [1].Thiazole derivatives were studied as potential anticancer drug [2,3]. Moreover, Triazole derivatives act as free radical scavengers and antioxidants, inhibiting lipid peroxidation and oxidative DNA damage, where the phenolic $(-\mathrm{OH})$ is the more active group of Triazole derivatives plays a major role in the activity of Triazole derivatives [4]. Also there are a variety of mechanisms for the antitumor action of Thiazole derivatives, acting on cancer bio targets, such as inosine monophosphate dehydrogenase (IMPDH) [5] and apoptosis inducers [6]. Inhibition of this enzyme results in a decrease in guanosine triphosphate (GTP) and deoxyguanosine triphosphate (dGTP) biosynthesis, producing inhibition of tumor cell proliferation. Multiple classes of Thiazole derivatives such as Schiff bases, mono-, di-, tri-, and heterocyclic substituents that possess anticancer activity have been exemplified. This molecular modeling of compounds predicts enhanced anticancer activity of the modified structures. So some new heterocyclic compounds containing a Thiazole ring were synthesized and used as anticancer 
with minimizing side effect and adverse effect. It also has large area for research with same biological activity. The beneficial Thiazole derivatives possessing anticancer activity will reignite the interest of medicinal chemists in Thiazole and their derivatives [7].

Apoptosis is a process of programmed cell death which is a vital component of various processes including normal cell turnover, hormone-dependent atrophy, and chemical-induced cell death Dysregulation of apoptotic signaling and inappropriate apoptosis (either too little or too much) is a factor in many diseases including many types of cancer. Cancer involves too little apoptosis (e.g., either by virus infection or by DNA mutations such as p53 and Bcl-2). The induction and execution of apoptosis require the cooperation of a series of molecules including signal molecules, receptors, enzymes and gene regulating proteins. Anti-apoptotic proteins regulate apoptosis by blocking the mitochondrial release of cytochrome-c, the pro-apoptotic proteins act by promoting such release. Balance between the pro- and anti-apoptotic proteins that determines whether apoptosis would be initiated [8].

The aim of this work was to investigate the antitumor activity and antioxidant status of Newly Synthesized Azole; against Ehrlich ascites carcinoma (EAC) tumor in mice. Furthermore, the effect of Azole derivative on the induction of apoptosis, proapoptotic (BAX), antiapoptotic (Bcl-2) and PARP was evaluated in an attempt to uncover the possible mechanism of action of such compound.

\section{Materials and Methods}

\section{Chemicals}

1. New synthetic compounds (Thiazoles).

2. Cisplatin (CDDP) is a Platinum compound (cis-Diamminedichloroplatinum), [9]. It was used as a standard anticancer drug. Cisplatin (MYLAN $10 \mathrm{mg}), 10 \mathrm{ml}(1 \mathrm{mg} / \mathrm{ml})$ ) was injected intraperitoneally to mice at a dose of $10 \mathrm{mg} / \mathrm{kg}$ body weight [10].

\section{Determination of median lethal dose (LD50)}

$\mathrm{LD}_{50}$ of azole was determined according to (11) five animals, which are distributed into five groups of one animal each. The animals are administered higher doses (10, 25, 50, 100 and $150 \mathrm{mg} /$ $\mathrm{kg}$ ) of test substance and then observed for 24 hours for behaviour as well as mortality.

Then the $\mathrm{LD}_{50}$ is calculated by the formula:

$$
\mathrm{LD}_{50}=\sqrt{\left(D_{0} \times D_{100}\right)}
$$

$\mathrm{D}_{0}=$ Highest dose that gave no mortality,

$\mathrm{D}_{100}=$ Lowest dose that produced mortality.

Experimental Animals:Studies were carried out using a total of The 120 adult female Swiss albino mice weighted (20-25g) purchased from animal House of the National Research Center, Dokki, Giza, Egypt, were used throughout this study, animal care followed the guidelines of the National Research Council . The animals were housed (animal house, faculty of Science, Damietta University) in specific pathogen-free conditions with an alternating12-hour light, dark cycle at ambient temperature of $20 \pm 1$ _C. Standard diet, commercial feed pellets and tap water were freely available.

Tumors Cells: Ehrlich ascites carcinoma (EAC) cells were obtained from Cancer Biology Section, National Cancer Institute, Cairo, Egypt. The Ehrlich tumor line was maintained, till the time of the experiment in female Swiss albino mice by serial (I.P) passage of $2.5 \times 106$ cells/mouse at 7-10 days intervals.

Experimental design: A total number of 120 adult female Swiss albino mice weighing 20-25 g were randomly assorted into 8 groups ( $\mathrm{n}=15 /$ group) as follows:

1) Group (1): were injected (I.P) with sterile saline $(0.2 \mathrm{ml} /$ mouse) for 10 days (day after day) act as a negative control.

2) Group (2): DEMSO were injected (I.P) with sterile Damson $(0.2 \mathrm{ml} /$ mouse day after day for 10 days).

3) Group (3): were inoculated (I.P) with (EAC) cell line, (2.5× 106 cells/ $0.2 \mathrm{ml} /$ mouse) once in the first day act as a Positive control.

4) Group (4): (Thiazole control) were injected were injected (I.P) with $200 \mu \mathrm{l}$ of Azole for 10 days in a dose $(50 \mathrm{mg} / \mathrm{kg}$ body wt. / day after day).

5) Group (5): (EAC + cisplatin) were inoculated (I.P) with (EAC) like the EAC control group, then injected with cisplatin in a dose (10 mg / kg body wt. , $0.2 \mathrm{ml} /$ mouse day after day for 10 days) as standard anticancer drug.

6) Group (6): (EAC + Thiazole $25 \mathrm{mg}$ ) were inoculated (I.P) with (EAC) like the EAC control group, then injected (I.P) with 200 $\mu \mathrm{l}$ of Azole for 10 days in a dose (25 mg / kg body wt. / day after day). Group (7): (EAC + Thiazole $50 \mathrm{mg}$ ) were inoculated (I.P) with (EAC) like the EAC control group, then injected (I.P) with $200 \mu \mathrm{l}$ of Azole for 10 days in a dose $(50 \mathrm{mg} / \mathrm{kg}$ body wt. /day after day).

7) Group (8): (EAC + Thiazole $75 \mathrm{mg}$ ) were inoculated (I.P) with (EAC) like the EAC control group, then injected (I.P) with 200 $\mu \mathrm{l}$ of Azole for 10 days in a dose $(75 \mathrm{mg} / \mathrm{kg}$ body wt. / day after day). After 10 days, the blood samples and EAC cells were collected from mice to measure tumor cell count and other parameters. Also, liver tissues were collected from animals for histological study.

8) Cell viability and Counting of EAC cells: The viability of EAC cells was determined by the Trypan Blue Exclusion Method [12], where the total and viable cells (non-stained) were counted at magnification $\mathrm{x} 40$; as the number of cells $/ \mathrm{ml}$ was determined in studed groups.

Evaluation of Tumor weight: The weight of mice was estimated before and after withdrawal of EAC fluid and the deference is the increase in weight and expressed in grams. 
Evaluation of Tumor volume: The volume of the EAC was detected by measuring tube in milliliters (ml) [13].

Determination of Percentage increase in life span (\%ILS): Mean survival time (MST) and \%ILS for each group were calculated according to the following formula [14], MST $=$ (no. of days to $1^{\text {st }}$ death + no. of days to last death) $/ 2$

\%ILS= [(MST of drug group / MST of control group) -1$] \times 100$

\section{Biochemical analysis}

Blood samples were collected after overnight fasting for biochemical Analysis. Sera were separated by centrifugation at 3000 $\mathrm{x} g$ for $10 \mathrm{~min}$ at room temperature and kept frozen $\left(-25^{\circ} \mathrm{C}\right)$ until analysis.Alanine transaminase (ALT), aspartate transaminase (AST) [15] and ALP alkaline phosphatase activities [16] and the concentration of creatinine [17] and urea [18] in serum were determined by colorimetric methods according to manufacturer's instructions (Spinreact,Spain) using semi-automated biochemistry analyzer 5010 photometer (Boehringer Mannheim).

\section{Evaluation of antioxidant parameters}

The activity of Super oxide dismutase (SOD) [20], reduced glutathione (GSH) [19] and malondialdehyde (MDA) [21] levels were determined by commercial kits (Biodiagonistics, Egypt) according to manufacturer's instructions.

\section{Determination of molecular markers}

Determination of serum apoptosis-related proteins proapoptotic BAX. (Rat Apoptosis Regulator (BAX), antipoptotic Bcl2 protein (Rat B-cell CLL/lymphoma 2 (BCL2)) and PARP levels (Rat poly-ADP-ribose polymerase) as a prognostic indicator for cancer was performed using ELIZA technique (solid phase sandwich ELISA assays) by commercial kits (MyBioSource) according to manufacturer's instructions.

\section{Histopathology evaluation}

The remaining portion of the same liver tissue was dissected and fixed in $10 \%$ formal saline embedded in paraffin, sectioned and stained with Hematoxylin and Eosin (H\&E).

\section{Statistical Analysis}

Statistical analysis was carried out using SPSS program version 14 [22]. Data were expressed as mean \pm SE. Student $(t)$ test and One-way ANOVA test were performed to detect the significance variation between test groups and control.

\section{Results}

\section{LD50 of thiazole}

In vivo toxicity study revealed that LD50 of azole was recorded at $100 \mathrm{mg} / \mathrm{kg}$

\section{Dose response on EAC count}

The most effective doses were finding to be 2550 and $75 \mathrm{mg} / \mathrm{kg}$ for azole and $10 \mathrm{mg} / \mathrm{kg}$ for cisplatin as this dose reduced the number of EAC cells in treated mice group up to $45 \% 62.5 \% 75 \%$ and $85 \%$ of EAC cells compared to positive control group.

\section{Effect of azole on tumor volume, count EAC cells and life span prolongation}

The number EAC cells decreased by $75 \%(\mathrm{P}<0.001)(50 \pm 5)$ million cell in $1 \mathrm{ml}$ with EAC treated with compound in concentration of $75 \mathrm{mg}$. decreased by $62.5 \%(\mathrm{P}<0.001)(50 \pm 5)$ million cell in $1 \mathrm{ml}$ after administration of azole 50 and decreased by $45 \%(\mathrm{P}<0.001)$

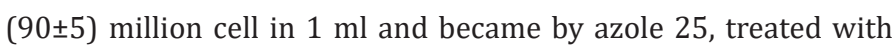
cisplatin it became $(30 \pm 7)$ by $85 \%$ when compared to EAC control group. The mean volume of EAC in positive control group was found to be $2.5 \pm 0.5(\mathrm{ml})$ as reported by [23].This value was significantly decreased by 40\%, 50.08\%60 \%and 72.3\% in Azol 25, 50 and $75 \mathrm{mg} / \mathrm{kg}$ and cisplatin treated groups; respectively. Moreover, the percent increase in life span reached $50 \%$ to reach 19 days $(\mathrm{P}<0.01)$ in the group 75 .increase $46 \%$ by azole 50 to reach 18 daysand increased by $26 \%$ by Thiazole 25 azole to reach 16.5 dayswhich receivedazole compared to EAC control group (Table 1).

Table 1: Shows effect of azole on tumor cell count, volume, Body weight difference and Life span or survival time. Data represented as mean \pm standard

\begin{tabular}{|c|c|c|c|c|c|c|c|c|}
\hline & Saline & DMSO & EAC & EAC*cisplatine & EAC *25 mg Thiazole & $\begin{array}{c}\text { EAC *50 mg Thi- } \\
\text { azole }\end{array}$ & $\begin{array}{c}\text { EAC *75 mg } \\
\text { Thiazole }\end{array}$ & $\begin{array}{c}\text { Thiazole } \\
\text { 50mg only }\end{array}$ \\
\hline $\begin{array}{c}\text { Tumor Cell Count } \\
\text { (x106 cells/L) }\end{array}$ & 0 & 0 & $200 \pm 12$ & $30 \pm 7$ & $90 \pm 5$ & $75 \pm 6$ & $50 \pm 5$ \\
\hline Tumor Volume (ml) & 0 & 0 & $.5 \pm 2.5$ & $0.7 \pm .1$ & $1.5 \pm .5$ & $1.25 \pm .5$ & $1 \pm .5$ \\
\hline $\begin{array}{c}\text { Body Weight Differ- } \\
\text { ence (gm) }\end{array}$ & $4 \pm .2$ & $4.1 \pm .3$ & $10 \pm 1.2$ & $5 \pm .5$ & $8 \pm .5$ & $6 \pm .3$ & $4.2 \pm .7$ \\
\hline Life Span Days & $\begin{array}{c}\text { Over } \\
33\end{array}$ & 31 & 13 & 19 & 16.5 & 18 & $4 \pm .2$ \\
\hline
\end{tabular}

\section{Effect of azole on biochemical parameters}

Liver functions: AST, ALT and ALP activities in positive control group was significantly $(\mathrm{p}<0.001)$ increased, compared to negative control group, the elevation of liver enzymes is an index of impaired liver functions due to cancer as observed in EAC group. While treatment with Azole 25, 50 and 75mg significantly $(\mathrm{p}<0.05)$ increased AST and ALT compared to negative control group and decreased $(p<0.05)$ them compared to positive control group, while ALP was 
highly $(\mathrm{p}<0.001)$. Cisplatin treatment slightly $(\mathrm{p}<0.05)$ increases them compared to negative control group while significantly $(\mathrm{p}<0.01)$ decreases them for ALT, $((\mathrm{p}<0.05)$ for AST and $(\mathrm{p}<0.001)$ ALP compared to positive control group.Moreover, injection with DMSO vehicle only had no effect on them while Thiazole $50 \mathrm{mg}$ only significantly $(\mathrm{p}<0.05)$ increased AST and ALT compared to negative control group, while ALP was highly $(\mathrm{p}<0.001)$ increased.

Serum kidney functions: Results of the present study demonstrated that serum creatinine and blood urea levels were significantly $(\mathrm{p}<0.001)$ increased in positive control group compared to negative control one. Moreover, treatment with Azole 25, 50 and $75 \mathrm{mg}$ and cisplatin significantly $(\mathrm{p}<0.001)$ increase serum creatinine in a dose manner compared to negative control, and significantly $(p<0.001)$ decreased its level in comparison to positive control group, While blood urea levels were significantly $(p<0.01)$ decreased in a dose of 50 and $75 \mathrm{mg}$ and $(\mathrm{p}<0.05)$ in a dose of $25 \mathrm{mg}$ and in cisplatin group. But DMSO vehicle had no effect of on kidney functions while Thiazole $50 \mathrm{mg}$ only slightly increases serum creatinine $(\mathrm{p}<0.001)$ and blood urea $(\mathrm{p}<0.01)$ levels.

\section{Effect of azole on the oxidative status}

Positive control group showing significant increase in MDA level $(\mathrm{p}<0.001)$ while GSH and SOD activity were significantly $(\mathrm{p}<0.001)$ decreased compared to negative control group. Treatment with Azole 25, 50 and $75 \mathrm{mg}$ and cisplatin significantly $(\mathrm{p}<0.001)$ decreased MDA level Meanwhile GSH was significantly $(p<0.001)$ and SOD $(\mathrm{p}<0.01)$ increased Compared to positive control group. Compared to negative control MDA level still significantly $(p<0.001)$ increased in Azole 25, $50 \mathrm{mg}$ groups but $(\mathrm{p}<0.05)$ in $75 \mathrm{mg}$ group whileGSH and SOD significantly decreased $(\mathrm{p}<0.001)$ at $25 \mathrm{mg}$, $(\mathrm{p}<0.01)$ at $50 \mathrm{mg}$ and $75 \mathrm{mg}$ for GSH but SOD Slightly $(\mathrm{p}<0.05)$ decreased. Moreover, MDA, SOD and GSH levels not affected significantly by DMSO vehicle only while Thiazole $50 \mathrm{mg}$ only significantly $(\mathrm{p}<0.05)$ decreased MDA level only(Table 2).

Table 2: Shows effect of azole on serum ALT, AST, ALP, Creatinine, Urea, MDA, GSH and SOD.

\begin{tabular}{|c|c|c|c|c|c|c|c|c|}
\hline & Saline & DMSO & EAC & EAC ${ }^{*}$ cisplatin & $\begin{array}{c}\text { EAC *25 mg } \\
\text { Thiazole }\end{array}$ & $\begin{array}{c}\text { EAC }{ }^{*} 50 \mathrm{mg} \\
\text { Thiazole }\end{array}$ & $\begin{array}{c}\text { EAC } 75 \mathrm{mg} \\
\text { Thiazole }\end{array}$ & $\begin{array}{c}\text { Thiazole } 50 \mathrm{mg} \\
\text { only }\end{array}$ \\
\hline ALT (U/L) & $41.4 \pm 0.3$ & $42.4 \pm 0.3^{\# \# \#}$ & $67.6 \pm 0.4^{* * *}$ & $46.7 \pm 0.4^{\# \#}$ & $57.4 \pm 0.7^{* \#}$ & $62.3 \pm 0.5^{*}$ & $66.4 \pm 0.8^{*}$ & $50.4 \pm 0.5^{* \#}$ \\
\hline AST (U/L) & $47.4 \pm 0.3$ & $48.3 \pm 0.3^{\# \# \#}$ & $88.5 \pm 0.4^{* * *}$ & $61.1 \pm 0.2^{* \#}$ & $64.2 \pm 0.2^{* \#}$ & $67.9 \pm 0.2^{* \#}$ & $73.1 \pm 1.1^{* \#}$ & $61.5 \pm 0.5^{* \#}$ \\
\hline $\operatorname{ALP}(\mathrm{U} / \mathrm{L})$ & $64.1 \pm 0.6$ & $71.6 \pm 0.5^{\# \# \#}$ & $276.5 \pm 1.8^{* * *}$ & 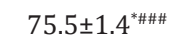 & $142.0 \pm 0.6^{* * * \#}$ & 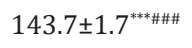 & 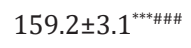 & $135.7 \pm 1.8^{* * * \# \# \#}$ \\
\hline $\begin{array}{c}\text { Creati- } \\
\text { nine }(\mathrm{mg} / \mathrm{dl})\end{array}$ & $0.87 \pm 0.02$ & 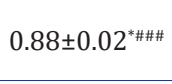 & $1.7 \pm 0.04^{* * * \# \# \#}$ & 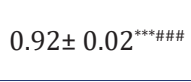 & 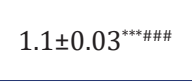 & 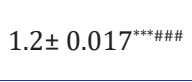 & $1.25 \pm 0.06^{* * * \# \# \#}$ & $0.91 \pm 0.03^{* * * \# \# \#}$ \\
\hline $\begin{array}{l}\text { Urea (mg/ } \\
\text { dl) }\end{array}$ & $44.7 \pm 0.2$ & $45.8 \pm 0.2^{\# \# \#}$ & $66.1 \pm 0.3^{* * \# \# \#}$ & $48.9 \pm 0.4^{* \# \# \#}$ & $52.7 \pm 0.7^{* \# \#}$ & $56.6 \pm 0.4^{* * \# \#}$ & $60.9 \pm 0.3^{* * \#}$ & $55.0 \pm 0.7^{* * \# \# \#}$ \\
\hline MDA (U/L) & $0.16 \pm 0.01$ & $0.17 \pm 0.01^{\# \# \#}$ & $0.47 \pm 0.01^{* * *}$ & $0.18 \pm 0.01^{* \# \# \#}$ & $0.39 \pm 0.01^{* * * \# \#}$ & $0.37 \pm 0.01^{* * * \# \#}$ & 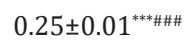 & $0.20 \pm 0.01^{* \# \# \#}$ \\
\hline GSH (U/L) & $0.37 \pm 0.02$ & $0.36 \pm 0.01^{\# \# \# 0}$ & $0.11 \pm .01^{* * *}$ & $0.30 \pm 0.01^{\# \# \#}$ & $0.19 \pm 0.04^{* * * \# \#}$ & $0.26 \pm 0.02^{* * \# \# \#}$ & $0.29 \pm 0.02^{* * \# \# \#}$ & $0.33 \pm 0.06^{\# \# \#}$ \\
\hline $\operatorname{SOD}(\mathrm{U} / \mathrm{L})$ & $0.55 \pm 0.01$ & $0.51 \pm 0.01^{\# \# \#}$ & $0.18 \pm 0.02^{* * *}$ & $0.47 \pm 0.01^{* \# \# \#}$ & $0.22 \pm 0.04^{* * * \# \#}$ & $0.32 \pm 0.01^{* \# \# \#}$ & $0.40 \pm 0.02^{* \# \# \#}$ & $0.42 \pm 0.01^{\# \# \#}$ \\
\hline
\end{tabular}

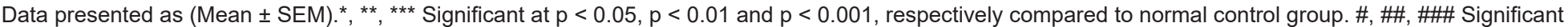
at $p<0.05, p<0.01$ and $p<0.001$, respectively compared to EAC control group.

Data presented as (Mean \pm SEM).* ${ }^{* *},{ }^{* * *}$ Significant at $\mathrm{p}<0.05$, $\mathrm{p}<0.01$ and $\mathrm{p}<0.001$, respectively compared to normal control

group. \#, \#\#, \#\#\# Significant at $\mathrm{p}<0.05, \mathrm{p}<0.01$ and $\mathrm{p}<0.001$, respectively compared to EAC control group.

\section{The effect of azole on anti-tumor parameters (BAX, BCL2 and PAPP)}

Table 3: Show effect of azole on BAX, Bcl2 and PAPP.

\begin{tabular}{|c|c|c|c|c|c|c|c|c|}
\hline & Saline & DMSO & EAC & EAC *isplatin & $\begin{array}{l}\text { EAC }^{*} 25 \mathrm{mg} \\
\text { Thiazole }\end{array}$ & $\begin{array}{l}\text { EAC *50mg } \\
\text { Thiazole }\end{array}$ & $\begin{array}{l}\text { EAC }{ }^{*} 75 \mathrm{mg} \text { Thi- } \\
\text { azole }\end{array}$ & $\begin{array}{c}\text { Thiazole } 50 \mathrm{mg} \\
\text { only }\end{array}$ \\
\hline $\begin{array}{c}\text { BAX(ng/ } \\
\text { mL) }\end{array}$ & $\begin{array}{c}0.47 \pm \\
0.08\end{array}$ & $\begin{array}{l}0.45 \pm \\
0.01^{\# \# \#}\end{array}$ & $\begin{array}{l}0.19 \pm \\
0.03^{* *+*}\end{array}$ & $0.34 \pm 0.01^{* \# \# \#}$ & $0.23 \pm 0.01^{* * \#}$ & $0.30 \pm 0.08^{* * \# \#}$ & $0.35 \pm 0.04^{* * \# \# \#}$ & $0.36 \pm 0.01^{* * * \# \#}$ \\
\hline $\begin{array}{c}\text { Bcl2(ng/ } \\
\text { mL) }\end{array}$ & $\begin{array}{c}0.28 \pm \\
0.01\end{array}$ & $\begin{array}{l}0.26 \pm \\
0.01^{\# \# \#}\end{array}$ & $\begin{array}{l}0.75 \pm \\
0.02^{ \pm *+}\end{array}$ & 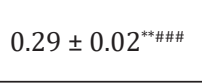 & 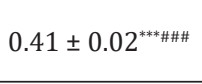 & 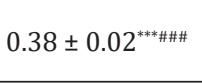 & $0.31 \pm 0.04^{* * \# \# \#}$ & $0.27 \pm 0.04^{\# \# \#}$ \\
\hline $\begin{array}{c}\text { PARP(ng/ } \\
\text { mL) }\end{array}$ & $\begin{array}{c}0.24 \pm \\
0.03\end{array}$ & $\begin{array}{l}0.25 \pm \\
0.01^{\# \# \#}\end{array}$ & $\begin{array}{l}0.42 \pm \\
0.01^{* * *}\end{array}$ & $0.26 \pm 0.01^{\# \# \#}$ & 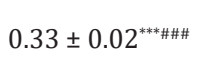 & $0.29 \pm 0.01^{* \# \# \#}$ & $0.28 \pm 0.01^{* \# \# \#}$ & $0.26 \pm 0.03^{\# \# \#}$ \\
\hline
\end{tabular}

Data presented as (Mean \pm SEM). ${ }^{*},{ }^{* *},{ }^{* * *}$ Significant at $p<0.05, p<0.01$ and $p<0.001$, respectively compared to normal control group. \#, \#\#,\#\# Significant at $p<0.05, p<0.01$ and $p$

BAX level was highly significantly $(\mathrm{p}<0.001)$ decreased while BCL2 and PARP were significantly $(\mathrm{p}<0.001)$ increased in Positive control group. Treatment with Azole 2550and $75 \mathrm{mg}$ and cisplatin significantly increased BAX butdecreased BCL2 and PARPcompared to Positive control groups, Furthermore, BAX, BCL2 and PARP levels not affected by DMSO vehicle only while Thiazole $50 \mathrm{mg}$ only significantly $(\mathrm{p}<0.001)$ decreased BAX and PARP levels Compared to negative control, but BCL2 level not affected (Table 3). 
Data presented as (Mean \pm SEM).*,**,*** Significant at $\mathrm{p}<0.05$, $\mathrm{p}<0.01$ and $\mathrm{p}<0.001$, respectively compared to normal control group. \#, \#\#, \#\#\# Significant at $\mathrm{p}<0.05, \mathrm{p}<0.01$ and $\mathrm{p}<0.001$, respectively compared to EAC control group. (Figure 1,2)

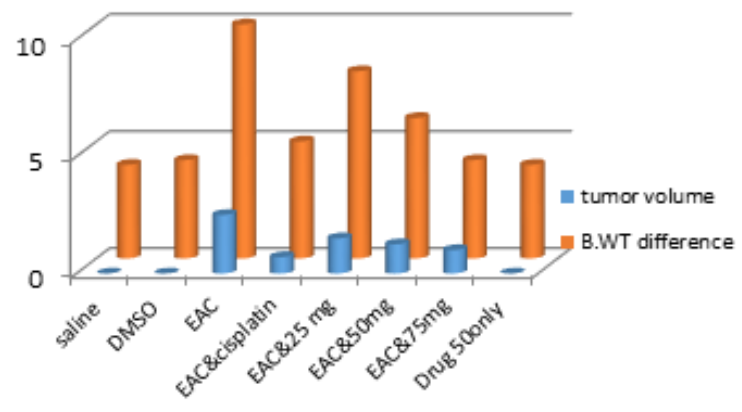

Figure 1: Show effect of tumor volume and B.WT difference.

Figure 2: Show effect of tumor volume and B.WT difference.

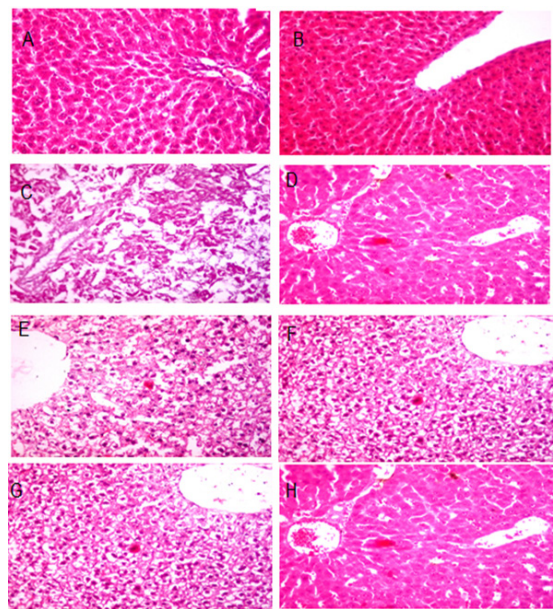

Figure 3: (A) Negative control group lobule the hepatocytes are arranged as cords of cells connecting the portal tracts in the periphery to the central vein s (terminal branch of hepatic veins) Between cords of hepatocytes are a specialized. (B) DMSO like negative control group. (C) EAC .The degenerative and proliferative lesions and showed some histologic lesions such as individual hepatocellular necrosis cellular vacuolation and spongoisis hepatitis changes. (D) EAC with Cisplatin showing restoration of hepatic architecture with focal hemorrhage. (E) EAC with drug $25 \mathrm{mg}$ Hepatocellular degeneration and necrosis were commonly seen as marked individhal cell ballooning degeneration with lysis. (F) EAC with drug 50mg Dilatations in sinusoids and cystic degeneration (characterized by large empty spaces in the parenchyma, often appearing to originate adjacent to Disse space) were commonly present. (G) EAC with drug $75 \mathrm{mg}$ Partial restoration of architecture with inflammatory cells infiltrate. $(\mathrm{H})$ Drug 50 only Hepatocellular vacuolation was a common change seen throughout the study, and was present in either discrete foci or in more diffuse distributions involving large portions of the parenchyma. As vacuolated foci often appeared mixed and further histochemical evaluation was not performed, they were all grouped under the more general heading. 


\section{Discussion}

The present study was carried out to prove the efficacy of new Thiazole derivatives as antitumor effect on Ehrlich Ascites Carcinoma. Ehrlich ascites carcinoma is a spontaneous murine mammary adenocarcinoma adapted to ascites form and carried in outbred mice by serial intraperitoneal (i/p) passages [24], so it is used frequently to study the antitumor efficacy of many EAC is prepared in mice as fluid to form ascetic tumor and inoculated in mice in groups with definite concentration by using cisplatin as classic standard anti-cancer drug which linked to ability to crosslink with purine bases on the DNA to induce apoptosis in cancer cells. Cisplatin is one of the most potent anticancer drugs available today and is widely used in the treatment of many malignancies, including testicular, ovarian, bladder, head and neck, small cell and non-small cell lung cancers. However, its use is associated with severe side effects, such as acute nephrotoxicity and chronic neurotoxicity [25].Thiazole derivatives have prominent DNA-binding affinity [26]. Heterocyclic compound chemistry continues to be an explore field in the Pharmaceutical or organic chemistry and the importance of Thiazole derivatives lies in that they have occupied a unique position in heterocyclic chemistry, due to its various biological activities [27].

In vivo antitumor effectiveness toward EAC in mice. Three substantial measurements were detected for estimation of antitumor effectiveness of the Thiazole and cisplatin (reference agent). Life span of tumor bearing mice, tumor volume and count of viable cells. It was observed that a significant increase in life span of the EAC of treated mice. This increase in life span of tumor bearing mice, Decrease in tumor volume and count of viable cells are evidence for efficacy of Thiazole compound. Thus, the present results support the conclusion of [28] who studied the beneficial effects of triazol compounds which may able to increase cellular stress resistance.

After treatment with Thiazole Liver function values of enzymes ALT,AST and ALP were elevated gradually with increase of Thiazole concentration compared to negative control group, while cisplatin treatment decreased them near to the to negative control group. This was because of Thiazole compound has a cytotoxic effect results in liver injury causing elevation in secretion of liver enzymes that supported by histopathological examination of liver which was presented in either discrete foci or in more diffuse distributions involving large portions of the parenchyma. Similar observation which supports this was reported by [29] where found that although all Triazole benefits, it cause impairment of hepatocyte function will increase the activity/toxicity of low-clearance drugs which require metabolic detoxification by the liver. These hepatotoxic reactions are among the most common, and potentially serious, adverse effects associated with triazole therapy.

Current results revealed that, Thiazole treatment in a dose level of 25,50 and $75 \mathrm{mg}$, also cisplatin reduced the elevated levels of serum urea and creatinine compared to positive control group, but cannot down regulate them compared to negative control group, these was attributed to be due to deterioration in renal function. As apparent from our data in group (4) which treated with Thiazole 50 mg only where showed a slight nephrotoxic effect. Similar observation which supports this was reported by [29] who also demonstrated that Thiazole derivatives not recommended to be used in patients with renal impairment.

The human body has a complex antioxidant defense system which blocks the initiation of free radical chain reactions [30]. Degenerative diseases of aging as cancer are attributed to cell damage caused by free radicals [31]. Oxidative stress is the set of intracellular and extracellular conditions that lead to chemical or metabolic generation of reactive species. There is a balance between factors that exhibit antioxidant capability and those that exert oxidative stress [32]. Presence of MDA in excess is due to its oxidative damage of lipoproteins, cell membrane and other lipid containing structures [33], and increased in carcinomatous tissue than in non-disease organs [34]. Oxidative stress decreases the GSH and changes the glutathione redox state of different tissues to GSSG, this increase may be caused by an increase in peroxide production by tumor cells that can lead to oxidation of GSH [35]. SOD Enzyme has a vital role in the follow up of cancer disease. These enzymes counteract the deleterious effect of Reactive Oxygen Metabolites (ROMs) such as singlet oxygen $\left({ }^{1} \mathrm{O}_{2}\right)$, super oxide anions $\left(\mathrm{O}_{2}^{\bullet}\right)$, Hydroxyl radical $\left({ }^{0} \mathrm{OH}\right)$ hydrogen peroxide $\left(\mathrm{H}_{2} \mathrm{O}_{2}\right)$. Several researches were considered SOD enzyme acts as antitoxins, anti-carcinogens and inhibitor at initiation, promotion and transformation of carcinogenesis [36].

As apparent from our data the treatment with Thiazole in a dose of 25, 50 and 75mg, try to reduce the MDA levelwhich gradually significant decreased by increasing the dose of treatment compared to positive control group but cannot reach near the negative control level as treatment with cisplatin. In contrary GSH and SOD activity were gradually increased in a dose dependent manner compared to positive control group and cannot also reach near the negative control level as in cisplatin treated group. Our results are in agreement with [29] who reported that Triazole derivatives act as antioxidants and free radical scavengers, inhibiting lipid peroxidation and oxidative DNA damage, Based on various experimental and theoretical results it is definitely concluded that the phenolic $(-\mathrm{OH})$ plays a major role in the activity of Triazole derivatives.

The anticancer activities for Thiazole were found to be through the regulation of different pathways that induce apoptotic pathway via the elevation of the proapoptotic BAX protein and the inhibition of the antiapoptotic Bcl-2 protein and PARP. Bcl-2 (B-cell CLL/ lymphoma 2) protein is localized in the nuclear envelope, endoplasmic reticulum and outer mitochondrial membrane [37]. There are two main groups of the Bcl-2 proteins, namely the pro-apoptotic proteins (e.g. Bax, Bak, Bad, Bcl-Xs, Bid, Bik, Bim and Hrk) and the anti-apoptotic proteins (e.g. Bcl-2, Bcl-XL, Bcl-W, Bfl-1 and Mcl-1). While the anti-apoptotic proteins regulate apoptosis by blocking the mitochondrial release of cytochrome-c, the pro-apoptotic pro- 
teins act by promoting such release. It is not the absolute quantity but rather the balance between the pro- and anti-apoptotic proteins that determines whether apoptosis would be initiated19. [38]. When cells are in rest, the pro-apoptotic BAX remain inactive by interaction with BCL2 both on the mitochondrial as well as endoplasmic reticulum (ER) membranes.

PARP is a nuclear zinc finger DNA-binding protein that detects and binds to DNA strand breaks. During apoptosis process, this specific protein called Poly (ADP-ribose) polymerase (PARP) appears to be targeted for proteolytic cleavage [39]. The PARP reaction catalysis the cleavage of NAD+ into nicotinamide and ADP-ribose leading to the rapid consumption of NAD+ when DNA is damaged by alkylating agents [40]

In the present study tumor bearing mice showed a significant decrease in serum BAX while $\mathrm{Bcl} 2$ and PARP levels were significantly increased. Thiazole in a doses of 25,50 and $75 \mathrm{mg}$, try to make upregulation of BAX and downregulation of Bcl2 and PARP level gradually by increasing the dose of treatment in a dose dependent manner compared to positive control group as treatment with cisplatin, while compared to negative control group PARP reaches near to the normal level in a dose of $75 \mathrm{mg}$ but BAX and $\mathrm{Bcl} 2$ cannot reach near the negative level similar to cisplatin. It is clear from the present findings that Thiazole act as apoptosis inducer. Similarly Cisplatin mode of action has been linked to its ability to crosslink with the purine bases on the DNA; interfering with DNA repair mechanisms, causing DNA damage, and subsequently inducing apoptosis in cancer cells [41]. Moreover, Shewach and Kuchta, (2009) [42] Explain that Azole derivatives act as antioxidants and free radical scavengers, inhibiting lipid peroxidation and oxidative DNA damage, the phenolic $(-\mathrm{OH})$ plays a major role in the activity of Azole derivatives This would explain our present findings and is also in agreement with it.

This was emphasized by [39] who reported that Biochemistry of apoptosis is the proteolytic cleavage and inactivation of PARP in the execution phase of cell death; moreover, in case of apoptosis inhibited by whichever mechanism (Bcl-2 overexpression, use of caspase-specific inhibitors, etc.) PARP cleavage is also inhibited. PARP-deficient Cells Are Highly Sensitive to Apoptosis Induced and the cell need to get rid of this protein to bring about apoptosis where a specific degradation of chromatin is a key component of the apoptotic process. Absence of PARP in fragile cell leads to accumulation of damaged unrepaired DNA and this explain it's undergo apoptosis faster than parental cells. Taken together these results come to a conclusion that Thiazole is considered as (PARP) inhibitor.

\section{Conclusion}

Finally, this work highlights the antitumor activity of Thiazole against EAC in mice. Treatment of mice bearing tumor with Thiazole induced tumor growth regression and showed antioxidant activity by increasing the deteriorated levels of GSH and SOD and reduce the MDA level in untreated groups and decreasing their elevated lipid peroxidation. Induced apoptosis through activation of proapoptotic protein (BAX), and downregulated antiapoptotic protein (Bcl-2) and PARP. But, has hepatotoxic effect through elevated levels of liver enzymes and slightly effect on kidney function parameters.

\section{Acknowledgment}

None.

\section{Conflict of Interest}

No conflict of interest.

\section{References}

1. Saleh A Bahashwan, Ahmed A Fayed, Mohamed A Ramadan, Abd El Galil E Amr, Naif O Al-Harbi (2014) Androgen Receptor Antagonists and AntiProstate Cancer Activities of Some Newly Synthesized Substituted Fused Pyrazolo-, Triazolo- and Thiazolo-Pyrimidine Derivatives. Int J Mol Sci 15: 21587-21602

2. Rida SM, Habib NS, Badawey EA, Fahmy HT, Ghozlan HA (1996) Synthesis of novel Thiazole [4,5-d]pyrimidine derivatives for antimicrobial, antiHIV and anticancer investigation. Pharmazie 51: 927-931.

3. Fahmy HT, Rostom SA, Bekhit AA (2002) Synthesis and antitumor evaluation of new polysubstitutedthiazole and derived Thiazole [4, 5-d] pyrimidine systems. Arch Pharm(Weinheim) 335: 213-222.

4. Yang SS, Huang CC, Chen JR, Chiu CL, Shieh MJ, et al. (2005) Effects of ethanol on antioxidant capacity in isolated rat hepatocytes. World J Gastroenterology 11: 7272-7276.

5. Matsuya Y, Kawaguchi T, Ishihara K, Ahmed K, Zhao QL, et al. (2006) Synthesis of macrosphelides with a thiazole side chain: New antitumor candidates having apoptosis-inducing property. Org Lett 8: 4609-4612.

6. Leoni A, Locatelli A, Morigi R, Rambaldi M (2014) Novel thiazole derivatives: A patent review (2008-2012 Part 2). Expert OpinTherPat 24: 759-777.

7. Shweta Jain, SatyanarayanPattnaik, Kamla Pathak, Sushant Kumar, Devender Pathak, et al. (2018) Minireviews in medicinal chemistry. Mini-Reviews in Medicinal Chemistry Journal.

8. Anita, HP Sharma, Paras Jain, Patnaik Amit (2014) APOPTOSIS (PROGRAMMED CELL DEATH)-A REVIEW World Journal of Pharmaceutical Research 3(4): 1854-1872

9. Matsusaka S,Nagareda T, Yamasaki H (2005) Does cisplatin (CDDP) function as a modulator of 5-fluorouracil (5-FU) antitumor action? A study based on a clinical trial. Cancer Chemother Pharmacol 55:387392.

10. George M, Era T, Sylva H,Michael L, Konstantinos A (2009) In vivo investigation of tolerance and antitumor activity of cisplatin-loaded PLGA-mPEG nanoparticles.Eur J Pharm Biopharm 71: 190-195.

11. Chinedu E, Arome D, Ameh FS (2013) A New Method for Determining Acute Toxicity in Animal Models. Toxicol Int 20(3) 224-226.

12. McLiman WF, Daris EV, Dluver FL, Rake GW (1957) The submerged culture of mammalian cells; The spring culture. J Immunol 79: 428.

13. Sneha Mishra, Ankit Kumar Tamta, Mohsen Sarikhani, Perumal Arumugam Desingu, Shruti MKizkekra, et al. (2018) Subcutaneous Ehrlich ascites carcinoma mice model for studying cancer-induced cardiomyopathy. Scientific Reports 8(Article number: 5599).

14. Faten Z Mohamed, Mohamed S Elghreeb, Moustafa S Abdelhamid, Hazem A Elbazm (2018) Synthesis and Evaluation of the Antitumor Activity of (E)-3-((2-(5-(4-chlorophenyl) thiazol-2-yl)hydrazono) methyl) benzene-1,2-diol "In vitro and In vivo Study" In vivo Study" AJRB (2) $1-16$. 
15. Reitman S, Frankel S (1957) A Colorimetric Method for the Determination of Serum Glutamic Oxalacetic and Glutamic Pyruvic Transaminases. Am J Clin Pathol 28: 56-63.

16. Samuel D Jackson, H Brian Halsall, Amadeo J Pesce, William R Heineman (1993) Determination of serum alkaline phosphatase activity by electrochemical detection with flow injection analysis. Fresenius Journal of Analytical Chemistry volume 346: 859-862.

17. Rock RC, Walker WG, Jennings CD (1987) Nitrogen metabolites and renal function. In: Tietz NW, ed. Fundamentals of clinical chemistry. ( $3^{\text {rd }}$ Edn,) 669-704Philadellphia: WB Saunders, USA.

18. Putton C, Crouchd S (1977) Determination of serum blood urea nitrogen Anal Chem 464-469.

19. Beutler E, Duron O, Kelly B (1963) Improved method for the determination of blood glutathione. J Lab Clin Med 61: 882-890.

20. Nishikimi M, Roa NA, Yogi K (1972) BiochemBioph Res Common 46: 849-854.

21. Satoh K (1978) Serum Lipid Peroxide in cerebrovascular disorders determined by a new colorimetric method. Clin Chim Acta 90: 37-43.

22. Levesque R, SPSS (2007) Programming and Data Management: A Guide for SPSS and SAS Users $4^{\text {th }}$ (edn), SPSS Inc, Chicago.

23. Amer YE (1986) Studies on the effect of Dietary Magnesium amd manganese on Experimental Tumour Cell (in mice). Thesis, Ain-Shams University, pp. 35.

24. Saravana KJ, Dilip M, Wani ZA, Harish CP, Mahitosh M (2010) Effect of Honey and Eugenol on Ehrlich Ascites and Solid Carcinoma. J Biomed Biotechnol: 989163.

25. George M, Era T, Sylva H, Michael L, Konstantinos A (2009) In vivo investigation of tolerance and antitumor activity of cisplatin-loaded PLGA-mPEG nanoparticles. Eur J Pharm Biopharm 71(2): 190-195

26. Abouzeid LA, ElSubbagh HI (2015) Microwave-assisted synthesis and antitumor evaluation of a new series of thiazolylcoumarin derivatives. FutureJPharm Sci 1: 1-7.

27. Neha S, Sharma PK, Rupesh D, Nitin K (2011) Recent advancement of triazole derivatives and their biological significance. J Chem Pharm Res 3(2): 126-133.

28. Mekheimer RA, Ahmed ARS, Eltaib AA (2012) Novel 1, 2, 4-Triazolo [1, 5-a] pyridines and Their Fused Ring Systems. Attenuate Oxidative Stress and Prolong Lifespan of Caenorhabiditis Elegans. J Med Chem 55(9): 4169-4177.
29. Zahran FM, AbdelLatif FF, Sayed AR, Rabab Shaban, Akaber TKeshta (2013) Biological studies of the effect of some new synthetic triazole derivatives on ehrlich ascites carcinoma cells. International Journal of Biological \& Pharmaceutical Research 4(4): 261-270.

30. RaoDN, Desai PB, GaneshB (1996) Epidemiological observation on cancer of the esophagus- a review of Indian studies. Ind J Cancer 33(2): 55-75.

31. Langseth L (1993) Antioxidants and diseases of the brain: Antioxidant vitamin. Newsletters 4: 3

32. MercuriF, QuagliaroL, Cerliello A (2000) Oxidative stress evaluation in diabeted. Diabetes TechnTher 2: 589.

33. Girotti AWJ (1998) Lipid Res 39: 1529.

34. KaynarH, MeralM, TurhanH, Keles M, Celik G, et al. (2005) Cancer Lett 227: 133.

35. Badr ElDin NK (2004) Protective role of sanumgerman against y-irradiation-induced oxidative stress in Earlich carcinoma-bearing mice. Nutrition recerch24: 271-291.

36. Ankita Sahu, Meena Varma, Kamal Kachhawa (2013)A Prognostic Study of MDA, SOD and Catalase in Breast Cancer Patients. International JSciRes: 2319-7064.

37. Krajewski S, Tanaka S, Takayama S, Shibler MJ, Fenton W, et al. (1993) Investigations of the subcellular distribution of the Bcl-2 oncoprotein: Residence in the nuclear envelope, endoplasmatic reticulum, and outer mitochondrial membranes. Cancer Res53(19): 4701-4714.

38. ReedJC (1997) Bcl-2 family proteins: regulators of apoptosis and chemoresistance in haematologic malignancies. Semin Haematol34(4 suppl): 9-19.

39. Javier FOliver, Guadalupe de la Rubia, Ve'roniqueRolli, Carmen RuizRuiz M, Gilbert de Murcia, et al. (1998) Importance of Poly(ADP-ribose) Polymerase and Its Cleavage in Apoptosis.The Journal of Biological Chemistry 273(50): 33533-33539.

40. Purnel MR, Whish WJ (1980) Novel inhibitors of poly(ADP-ribose) synthetase. Biochem J185(3): 775-777.

41. Dasari S,Tchounwou PB (2014) Cisplatin in cancer therapy: molecular mechanisms of action. Eur J Pharmacol740: 364-378.

42. ShewachDS, Kuchta RD (2009) Introduction to cancer chemotherapeutics. Chemical rev 109(7): 2859-2861. 